\title{
BMJ Global Health Are low and middle-income countries prioritising high-value healthcare interventions?
}

\author{
Ashley A Leech (D , , ${ }^{1,2}$ David D Kim, ${ }^{2}$ Joshua T Cohen, ${ }^{2}$ Peter J Neumann ${ }^{2}$
}

To cite: Leech AA, Kim DD, Cohen JT, et al. Are low and middle-income countries prioritising high-value healthcare interventions? BMJ Global Health 2020;5:e001850. doi:10.1136/ bmjgh-2019-001850

Handling editor Seye Abimbola

- Additional material is published online only. To view please visit the journal online (http://dx.doi.org/10.1136/ bmjgh-2019-001850)

Received 17 July 2019 Revised 13 December 2019 Accepted 22 December 2019

Check for updates

(c) Author(s) (or their employer(s)) 2020. Re-use permitted under CC BY. Published by BMJ.

${ }^{1}$ Department of Health Policy, Vanderbilt University School of Medicine, Nashville, Tennessee, USA

${ }^{2}$ Center for the Evaluation of Value and Risk in Health, Institute for Clinical Research and Health Policy Studies, Tufts Medical Center, Boston, Massachusetts, USA

Correspondence to Dr Ashley A Leech; ashley.leech@vanderbilt.edu

\section{ABSTRACT}

Introduction Since resources are finite, investing in services that produce the highest health gain 'return on investment' is critical. We assessed the extent to which low and middle-income countries (LMIC) have included cost-saving interventions in their national strategic health plans. Methods We used the Tufts Medical Center Global Health Cost-Effectiveness Analysis Registry, an open-source database of English-language cost-per-disability-adjusted life year (DALY) studies, to identify analyses published in the last 10 years (2008-2017) of cost-saving health interventions in LMICs. To assess whether countries prioritised cost-saving interventions within their latest national health strategic plans, we identified 10 countries, all in sub-Saharan Africa, with the highest measures on the global burden of disease scale and reviewed their national health priority plans. Results We identified 392 studies (63\%) targeting LMICs that reported 3315 cost-per-DALY ratios, of which 207 ratios $(6 \%)$ represented interventions reported to be cost saving. Over half (53\%) of these targeted sub-Saharan Africa. For the 10 countries we investigated in subSaharan Africa, 58\% (79/137) of cost-saving interventions correspond with priorities identified in country plans. Alignment ranged from 95\% (21/22 prioritised cost-saving ratios) in South Africa to 17\% (2/12 prioritised cost-saving ratios) in Cameroon. Human papillomavirus vaccination was a noted priority in $70 \%(7 / 10)$ of national health prioritisation plans, while $40 \%(4 / 10)$ of countries explicitly included prenatal serological screening for syphilis. HIV prevention and treatment were stated priorities in most country health plans, whereas $40 \%(2 / 5)$ of countries principally outlined efforts for lymphatic filariasis. From our sample of 45 unique interventions, $36 \%$ of interventions (16/45) included costs associated directly with the implementation of the intervention.

Conclusion Our findings indicate substantial variation across country and disease area in incorporating economic evidence into national health priority plans in a sample of sub-Saharan African countries. To make health economic data more salient, the authors of cost-effectiveness analyses must do more to reflect implementation costs and other factors that could limit healthcare delivery.

\section{INTRODUCTION}

The 2030 Sustainable Development Goals call for greater access to affordable medications and interventions. ${ }^{12}$ Since its launch, many

\section{Key questions}

What is already known?

- Cost-effectiveness analyses can help decision makers maximise health gains per dollar spent on care a tool that is particularly helpful amid restricted budgets.

- Several initiatives encourage integration of economic evaluation into countries' prioritisation planning.

\section{What are the new findings?}

- Our findings indicate substantial variation across country and disease area in incorporating economic evidence into national health priority plans in subSaharan Africa.

- Most countries prioritised cost-saving interventions for human papillomavirus and HIV prevention and treatment; however, country prioritisation plans either omitted or were ambiguous regarding other cost-saving intervention areas such as antenatal syphilis screening and efforts towards specific neglected tropical diseases.

What do the new findings imply?

- Operational costs and other contextual factors may play a larger role than economic evidence in decision-making. It is therefore important that authors of cost-effectiveness analyses incorporate implementation and other contextual constraints into their evaluations that could limit healthcare delivery.

- Our list of cost-saving interventions can provide a good starting point for policymakers setting healthcare prioritisation plans for low and middle-income countries.

low and middle-income countries (LMIC) have made progress towards provision of universal healthcare coverage by prioritising access to essential services. ${ }^{3-12}$ That progress, however, has been slow. ${ }^{10}{ }^{13}$ Health priority plans, sometimes referred to as 'essential package of health services' or 'health benefit packages', outline services that a government is providing or aspires to provide. ${ }^{14-17}$ Because resources are scarce, investing in 'high-value' health services, that is, those that produce the highest health gain 'return on investment', is critical. 
Several initiatives encourage integration of economic evaluation into countries' prioritisation planning. ${ }^{3} 611$ 18-21 The Disease Control Priorities Network, for instance, proposes a 'model' benefits package that includes a subset of high-priority interventions (ie, interventions $<\$ 200 /$ disability-adjusted life years (DALY) averted for low-income countries and $<\$ 500 /$ DALY for lower middle-income countries). ${ }^{2022}$

Our paper assesses whether LMICs have included 'cost-saving' health interventions in national health priority plans-that is, interventions that are projected to both improve population health and reduce costs by, for example, preventing expensive, downstream adverse health events. The main purpose of our study centres on the importance of using economic evidence in country priority setting.

\section{METHODS}

\section{Global Health Cost-Effectiveness Analysis Registry}

The Tufts Medical Center Global Health Cost-Effectiveness Analysis (GHCEA) Registry, sponsored by the Bill and Melinda Gates Foundation, is a comprehensive database of English-language peer-reviewed cost-effectiveness analyses (CEA) containing 620 cost-per-DALY studies published through 2017 (updates are ongoing) (see the online supplementary appendix for a detailed overview of the GHCEA Registry). Of these 620 studies, we included CEAs applied to LMICs and published in the last 10 years (2008-2017) to reflect the latest medical interventions (table 1). We further classified cost-saving interventions by global burden of disease categories and reported the target country/region, target population, study perspective and time horizon (online supplementary appendix table 1).

\section{Assessment of countries' health priorities and cost-saving interventions}

To assess whether LMICs prioritised cost-saving interventions within their latest national health strategic

\begin{tabular}{|c|c|c|}
\hline Characteristic & $\begin{array}{l}\text { ICERS } \\
\text { n (\%) }\end{array}$ & $\begin{array}{l}\text { Articles } \\
\mathrm{n}(\%)\end{array}$ \\
\hline Cost saving* & 207 (6) & 33 (9) \\
\hline$<\$ 100 / D A L Y$ & $844(25)$ & $117(30)$ \\
\hline$\$ 100-\$ 1000 / D A L Y$ & $1206(36)$ & $144(37)$ \\
\hline$\$ 1001-\$ 10$ 000/DALY & 739 (22) & $66(17)$ \\
\hline$>\$ 10000 / D A L Y$ & $218(7)$ & 21 (5) \\
\hline Dominated & $86(3)$ & $5(1)$ \\
\hline Total & $\begin{array}{l}3315 \\
\text { (missing=15) }\end{array}$ & $\begin{array}{l}392 \\
\text { (missing=6) }\end{array}$ \\
\hline
\end{tabular}

*Interventions that are cost saving and health improving. DALY, disability-adjusted life year; ICER, incremental costeffectiveness ratio; LMIC, low and middle-income country. plans, we identified 10 countries with the highest global burden of disease ${ }^{23}$ and reviewed their health priority plans by gathering information on country government websites (eg, Federal Ministries of Health) and from US agencies (eg, US Agency for International Development). In cases where countries had additional disease-specific health plans, we also reviewed these (online supplementary appendix table 2 ). The 10 countries identified included: Cameroon, Lesotho, Liberia, Malawi, Nigeria, Sierra Leone, South Africa, Swaziland, Zambia and Zimbabwe.

We excluded countries for which we could not obtain health priority plans in English. We also omitted countries for which there were no reported cost-saving interventions (we excluded a total of 17 countries, listed in online supplementary appendix table 3). ${ }^{23}$ Next, we grouped all costsaving interventions for each identified country. In cases in which studies provided only one cost-saving estimate and/ or health gain estimate across multiple countries, we listed the intervention for each relevant country. For instance, there were five cost-saving interventions pertaining specifically to Malawi; however, there were 11 additional interventions that pertained to multiple countries that also included Malawi. We therefore included all 16 cost-saving interventions for Malawi and did the same for the other countries in our sample (online supplementary appendix table 2).

While the GHCEA Registry reflects data at the intervention level (eg, a specific test for prenatal syphilis screening), country policy documentation typically does not contain this level of detail. Therefore, we grouped each cost-saving intervention into a more general intervention category (eg, syphilis screening within antenatal visits) (online supplementary appendix table 2) and examined whether country health priority plans covered these broader health service areas. This approach was necessary to match our intervention-level data with less granular descriptions in each country's strategic health plan. For each cost-saving intervention area, we designated one of the following findings for each country: (1) available policy documentation matches cost-saving intervention area, (2) cost-saving intervention area unspecified in policy documentation, or (3) intervention area not included in available policy documentation.

We designated the 'unspecified' finding in cases in which an intervention area might be broadly implied but unspecified. For example, Zambia's Health Strategic Plan (2017-2021) outlines strategies for reducing the incidence of sexually transmitted infections. It also outlines a goal of strengthening services for antenatal care. ${ }^{24}$ However, it does not explicitly mention prenatal serological screening for syphilis, which is one of the cost-saving intervention areas in the Tufts GHCEA Registry. When we report on concordance, we accounted for studies only under the first category, ${ }^{1}$ that is, available policy documentation matches cost-saving intervention area. 
Table 2 LMIC GDP threshold-based categories (2008-2017)

\begin{tabular}{|c|c|c|c|c|c|c|}
\hline $\begin{array}{l}\text { Incremental cost-effectiveness ratio } \\
\text { categories }\end{array}$ & Cost saving & $<1 \times$ GDP & $1-3 \times$ GDP & $>3 \times$ GDP & Dominated & Total \\
\hline Cost saving & 207 & 0 & 0 & 0 & 0 & 207 \\
\hline$<\$ 100 / D A L Y$ & 0 & 844 & 0 & 0 & 0 & 844 \\
\hline$\$ 100-\$ 1000 / D A L Y$ & 0 & 1204 & 2 & 0 & 0 & 1206 \\
\hline$\$ 1001-\$ 10$ 000/DALY & 0 & 648 & 77 & 14 & 0 & 739 \\
\hline$>\$ 10$ 000/DALY & 0 & 78 & 66 & 74 & 0 & 218 \\
\hline Dominated & 0 & 0 & 0 & 0 & 86 & 86 \\
\hline Total & 207 & 2774 & 145 & 88 & 86 & 3300 \\
\hline
\end{tabular}

DALY, disability-adjusted life year; GDP, gross domestic product; LMIC, low and middle-income country.

\section{Patient and public involvement}

Patients nor the general public were involved in the design of this study.

\section{RESULTS}

\section{Cost-saving interventions in LMICs}

We identified 392 studies $(63 \%)$ targeting LMICs in the last 10 years that reported 3315 cost-per-DALY ratios, of which 207 ratios $(6 \%)$ represented interventions reported to be cost saving (table 2$)$. Over half $(53 \%)$ of the studies targeted interventions in sub-Saharan Africa. Communicable, maternal, neonatal and nutritional disorders made up the highest proportion $(61 \%)$ of cost-saving interventions, with HIV and tuberculosis comprising nearly half $(46 \%)$ of interventions within this category. Neglected tropical diseases and malaria comprised the second highest proportion (19\%) within the communicable disease category. Of the cost-saving interventions that targeted non-communicable diseases, over threequarters focused on neoplasms (59\%) and mental and other behavioural disorders (28\%) (table 3).

In addition, while $58 \%$ of cost-saving ratios $(120 / 207)$ included costs associated directly with the implementation of the intervention, $22 \%$ accounted for infrastructure, $40 \%$ administrative and $35 \%$ salary support (table 3).

\section{Inclusion of cost-saving interventions in countries' policy planning}

For the 10 countries we investigated in sub-Saharan Africa, we identified 17 studies detailing 45 interventions that were cost saving. When we accounted for 12 cost-saving interventions that applied to more than one country, there were 137 sets of savings and health gains across countries. From our sample of 45 unique interventions, $36 \%(16 / 45)$ included costs associated directly with the implementation of the intervention; $16 \%$ accounted for infrastructure costs, $31 \%$ administrative and 22\% salary support.

We found that $58 \%(79 / 137)$ of cost-saving interventions correspond with priorities identified in country plans (table 4). Concordance, however, varied across country and disease area. Alignment ranged from $95 \%$
(21/22 prioritised cost-saving ratios) in South Africa to $17 \%$ (2/12 prioritised cost-saving ratios) in Cameroon (table 4$)$.

The following initiatives were considered cost saving in each of the 10 countries in our sample: human papillomavirus (HPV) vaccination, antenatal syphilis screening and HIV prevention and treatment initiatives (such as expanded treatment, circumcision, HIV self-testing and initiatives for pregnant women to prevent child transmission) (online supplementary appendix table 2). HPV vaccination was a noted priority in $70 \%(7 / 10)$ of the national health prioritisation plans, while $40 \%(4 / 10)$ of countries explicitly included prenatal serological screening for syphilis. HIV prevention and treatment strategies were stated priorities in most country health plans; although Cameroon's plans did not explicitly outline efforts for male circumcision (online supplementary appendix table 2).

Moreover, a global programme to eliminate lymphatic filariasis was considered cost saving in half of our sampled countries (Malawi, Nigeria, Sierra Leone, Cameroon and Liberia), two (40\%) of which principally outlined efforts for lymphatic filariasis in their health policy priority plans. Online supplementary appendix table 2 details country-specific cost-saving interventions and their alignment with country national health plans.

\section{DISCUSSION}

Most countries prioritised cost-saving interventions for HPV and HIV prevention and treatment. Country prioritisation plans, however, either omitted or were ambiguous with regard to other cost-saving interventions, such as antenatal syphilis screening and efforts to address specific neglected tropical diseases. Given the burden of congenital syphilis in sub-Saharan Africa, the WHO recommends screening all women for syphilis at her first antenatal care visit, regardless of regional prevalence. ${ }^{25}$ Global efforts to eliminate neglected tropical diseases also remain a key health priority area for governments, with projected savings in the billions. ${ }^{2627}$

Data availability and capacity constraints could have hindered comprehensive policy planning. Other factors 


\begin{tabular}{lc|}
\hline $\begin{array}{l}\text { Table } 3 \\
\text { (cost-saving ratios)=207; } \mathrm{n} \text { (articles)=33 }\end{array}$ \\
\hline Targeted region* & $\mathbf{n}$ (ratios) (\%) \\
\hline $\begin{array}{l}\text { Central Europe, Eastern Europe and } \\
\text { Central Asia }\end{array}$ & $5(2 \%)$ \\
\hline Latin America and Caribbean & $24(12 \%)$ \\
North Africa and Middle East & $24(12 \%)$ \\
South Asia & $13(6 \%)$ \\
Southeast Asia, East Asia and Oceania & $58(28 \%)$ \\
Sub-Saharan Africa & $110(53 \%)$ \\
GBD classification $(\mathbf{n}=\mathbf{2 0 7})$ &
\end{tabular}

Communicable maternal, neonatal and

nutritional disorders $(n=126 ; 61 \%)$

Frequency missing $=3$

\begin{tabular}{lc}
$\begin{array}{l}\text { Diarrhoea, lower respiratory infections, } \\
\text { meningitis and other common infectious } \\
\text { diseases }\end{array}$ & $18(15 \%)$ \\
\hline HIV/AIDS and tuberculosis & $57(46 \%)$ \\
\hline Maternal disorders & $3(2 \%)$ \\
\hline Neglected tropical diseases and malaria & $23(19 \%)$ \\
\hline $\begin{array}{l}\text { Other communicable, maternal, neonatal } \\
\text { and nutritional disorders }\end{array}$ & $22(18 \%)$ \\
\hline Total & 123 \\
\hline $\begin{array}{l}\text { Non-communicable diseases (n=81; 39\%) } \\
\text { Frequency missing=1 }\end{array}$ & \\
\hline Mental and behavioural disorders & $23(28 \%)$ \\
\hline $\begin{array}{l}\text { Cardiovascular and circulatory diseases } \\
\text { Diabetes, urogenital, blood and } \\
\text { endocrine diseases }\end{array}$ & $4(5 \%)$ \\
\hline Neoplasms & $6(8 \%)$ \\
\hline Total & $47(59 \%)$ \\
\hline $\begin{array}{l}\text { Inclusion of implementation costs } \\
\text { (n=207) }\end{array}$ & 80 \\
\hline Specific components included & $120(58 \%)$ \\
\hline Infrastructure & \\
\hline Administrative & $46(22 \%)$ \\
\hline Salary & $83(40 \%)$ \\
\hline Other & $72(35 \%)$ \\
\hline
\end{tabular}

${ }^{*}$ Ratios can encompass more than one region (16 ratios target multiple countries). Therefore, the counts will add to greater than $100 \%$.

GBD, Global Burden of Disease; LMIC, low and middle-income country.

such as donor funding, implementation limits, equity issues or political realities ${ }^{28}$ may also play a larger role in decision-making than economic evidence from cost/ DALY studies. While cost-effectiveness information can help prioritise 'high-value' interventions, it might not capture short-term operational costs that could reduce or eliminate projected savings. ${ }^{6}{ }^{18}$ Indeed, only $36 \%$ of the sampled interventions included costs associated directly with the implementation of a service. Moreover, others
Table 4 Cost-saving interventions included in LMIC health prioritisation plans (10 sampled countries in sub-Saharan Africa, total of 137 sets of savings)

\begin{tabular}{|c|c|c|c|c|}
\hline Country & $\begin{array}{l}\text { n (ratios) } \\
(\%)\end{array}$ & $\checkmark$ & - & $\mathbf{x}$ \\
\hline \multicolumn{5}{|c|}{ Low-income economies* } \\
\hline Liberia & $12(8 \%)$ & $3(25 \%)$ & $9(75 \%)$ & $0(0 \%)$ \\
\hline Malawi & $16(11 \%)$ & $13(81 \%)$ & $0(0 \%)$ & $3(19 \%)$ \\
\hline Sierra Leone & $12(8 \%)$ & $11(92 \%)$ & $0(0 \%)$ & $1(8 \%)$ \\
\hline \multicolumn{5}{|c|}{ Lower middle-income economies } \\
\hline Cameroon & $12(9 \%)$ & $2(17 \%)$ & $0(0 \%)$ & $10(83 \%)$ \\
\hline Lesotho & $12(8 \%)$ & $4(33 \%)$ & $8(67 \%)$ & $0(0 \%)$ \\
\hline Nigeria & $13(9 \%)$ & $11(85 \%)$ & $2(15 \%)$ & $0(0 \%)$ \\
\hline Zambia & $14(10 \%)$ & $6(43 \%)$ & $8(57 \%)$ & $0(0 \%)$ \\
\hline Zimbabwe & $14(10 \%)$ & $6(43 \%)$ & $8(57 \%)$ & $0(0 \%)$ \\
\hline \multicolumn{5}{|c|}{ Upper middle-income economies } \\
\hline South Africa & $22(15 \%)$ & $21(95 \%)$ & $1(5 \%)$ & $0(0 \%)$ \\
\hline Swaziland & $10(7 \%)$ & $2(20 \%)$ & $0(0 \%)$ & $8(80 \%)$ \\
\hline Total & 137 & 79 (58\%) & $36(26 \%)$ & $22(16 \%)$ \\
\hline
\end{tabular}

$\checkmark$ Available policy documentation matches cost-saving intervention area.

- Cost-saving intervention area not explicitly specified.

$X$ Cost-saving intervention area not mentioned in available policy documentation.

*Defined by the World Bank (https://datahelpdesk.worldbank.org/ knowledgebase/articles/906519).

LMIC, low and middle-income country.

have suggested that rather than prioritising resources based on efficiency, governments should instead target health conditions imposing the greatest population burden. ${ }^{18} 1929$ That strategy, however, can omit particularly vulnerable groups such as those affected by neglected disease areas. ${ }^{26} 3031$

General limitations of this study include reliance on publicly available health policy documentation, which may be incomplete. For example, we collected some information regarding donor-government partnership, as donor plans often stated a collaborative partnership with applicable country ministries. However, our analysis may not capture a full range of multistakeholder partnership not listed in the policy documentation, and the level of the partnership can vary across countries. Moreover, our study relies on health policy goals rather than on direct measures of implementation. For instance, while Sierra Leone's basic package of essential health services (2015-2020) outlined goals for syphilis testing at antenatal care clinics, a recent study revealed that syphilis detection and treatment services were available in fewer than $5 \%$ of antenatal care facilities in Sierra Leone in $2015 .{ }^{3233}$ Further, our study takes a conservative approach to valuing services by identifying interventions deemed 'cost-saving', that is, interventions that are projected to both improve population health and reduce costs. Other initiatives have outlined interventions that are 
cost-effective or highly cost-effective based on predefined thresholds. ${ }^{5}$

Notwithstanding general study limits, these findings and corresponding appendices can be used by governments and other localised efforts to identify potential opportunities to reallocate resources to take advantage of highly efficient health interventions that they may not have been previously targeting.

\section{CONCLUSION}

Reflecting on the importance of using economic evidence in country priority setting, our paper assessed whether LMICs have included 'cost-saving' health interventions in national health priority plans. Our findings indicate substantial variation across country and disease area in how a sample of countries in sub-Saharan Africa incorporate economic evidence into national health priority plans. Countries may not place substantial emphasis on health economic findings because CEAs often omit important cost elements. For example, we found that fewer than half of the interventions in our sample included costs associated directly with the implementation of the intervention. Operational costs and other contextual factors may play a larger role than economic evidence in decision-making. To make health economic data more salient, authors of cost-effectiveness studies must do more to reflect other factors that could limit healthcare delivery. Future research may also address why some countries are integrating economic evidence into their policy planning compared with others. Donors and other competing factors could also be influential factors explaining these differences.

Contributors AAL is the guarantor of the article. All authors meet the four ICMJE criteria for authorship and worked collaboratively to contribute to the conceptual design, review and final approval of the published version. To prepare this manuscript, the authors systematically reviewed the Tufts Medical Center Global Health Cost-Effectiveness Analysis (GHCEA) Registry, a repository of Englishlanguage cost-per-DALY averted studies indexed in PubMed.

Funding The Bill and Melinda Gates Foundation.

Competing interests JTC has grants for work conducted on behalf of Amgen, Biogen and Janssen Pharmaceuticals and has lectured on the use of simulation for Pfizer. JTC has also consulted for AbbVie, Precision Health Economics, Sage Therapeutics and Sarepta. PN has held one-time roles on the advisory boards on health economics topics for Avexis, AbbVie, Research Triangle Institute, Merck, Genentech, Bluebird Bio and Novo Nordisk. PN serves on the advisory board for the Congressional Budget Office and has consulted for Precision Health Economics.

Patient consent for publication Not required

Provenance and peer review Not commissioned; externally peer reviewed.

Data availability statement Data are available in a public, open access repository. All data relevant to the study are included in the article or uploaded as supplementary information http://ghcearegistry.org/ghcearegistry/

Open access This is an open access article distributed in accordance with the Creative Commons Attribution 4.0 Unported (CC BY 4.0) license, which permits others to copy, redistribute, remix, transform and build upon this work for any purpose, provided the original work is properly cited, a link to the licence is given, and indication of whether changes were made. See: https://creativecommons.org/ licenses/by/4.0/.

\section{ORCID iD}

Ashley A Leech http://orcid.org/0000-0001-6795-929X

\section{REFERENCES}

1 United Nations Sustainable Development. Martin. sustainable development goals Launch in 2016, 2015. Available: https:// www.un.org/sustainabledevelopment/blog/2015/12/sustainabledevelopment-goals-kick-off-with-start-of-new-year/ [Accessed 14 Nov 2018].

2 United Nations Sustainable Development. The sustainable development agenda, 2018. Available: https://www.un.org/sustaina bledevelopment/development-agenda/ [Accessed 14 Nov 2018].

3 Glassman A, Giedion U, Sakuma Y, et al. Defining a health benefits package: what are the necessary processes? Health Syst Reform 2016;2:39-50.

4 World Health Organization. Universal health coverage (UHC). Available: http://www.who.int/news-room/fact-sheets/detail/ universal-health-coverage-(uhc) [Accessed 14 Nov 2018].

5 Watkins DA, Jamison DT, Mills A, et al. Universal Health Coverage and Essential Packages of Care. In: Jamison DT, Gelband H, Horton S, et al, eds. Disease control priorities: improving health and reducing poverty. 3rd edn. Washington (DC): The International Bank for Reconstruction and Development / The World Bank, 2017. http:// www.ncbi.nlm.nih.gov/books/NBK525285/

6 Glassman A, Giedion U, Smith PC. Priority-setting institutions in health: recommendations from a center for global development Working group. Glob Heart 2017;7:13-34.

7 OECD. Universal health coverage and Health-Outcomes. OECD, 2016. Available: https://www.oecd.org/els/health-systems/UniversalHealth-Coverage-and-Health-Outcomes-OECD-G7-HealthMinisterial-2016.pdf

8 World Health Organization, OECD, and International Bank for Reconstruction and Development/The World Bank. Delivering quality health services: a global imperative, 2018. Available: https://read. oecd-ilibrary.org/social-issues-migration-health/delivering-qualityhealth-services-a-global-imperative_9789264300309-en [Accessed 14 Nov 2018].

9 Glassman A, Chalkidou K, Giedion U, et al. Priority-setting institutions in health: recommendations from a center for global development Working group. Glob Heart 2012;7:13-34.

10 The World Bank.. Tracking universal health coverage : 2017 global monitoring report [Internet]. The World Bank; 2017 Dec [cited 2018 Nov 14] p. 1-88. Report No.: 122029. Available from:. Available: http://documents.worldbank.org/curated/en/640121513095868125/ Tracking-universal-health-coverage-2017-global-monitoring-report

11 Chalkidou K, Glassman A, Marten R, et al. Priority-setting for achieving universal health coverage. Bull World Health Organ 2016;94:462-7.

12 Smith PC, Chalkidou K. Should countries set an explicit health benefits package? the case of the English National health service. Value Health 2017;20:60-6.

13 The World Bank. UHC in Africa: a framework for action report no: 108008. The World Bank, 2016: 1-60. http://documents.worldbank. org/curated/en/735071472096342073/Main-report

14 Health Finance and Governance Project, USAID. Essential packages of health services in 24 countries: findings from a Cross-Country analysis. Available: https://www.hfgproject.org/essential-packageof-health-services-country-snapshot-malawi/ [Accessed 26 Nov 2018].

15 Health Finance and Governance Project, USAID. Essential packages of health services in 24 countries: findings from a Cross-Country analysis. Available: https://www.hfgproject.org/ephs-cross-countryanalysis/ [Accessed 26 Nov 2018].

16 Health Finance and Governance Project, USAID. Essential health services: Zambia HFG. Available: https://www.hfgproject.org/ essential-package-of-health-services-country-snapshot-zambia/ [Accessed 26 Nov 2018].

17 Health Finance and Governance Project, USAID. Essential health services: Nigeria HFG. Available: https://www.hfgproject.org/ essential-package-of-health-services-country-snapshot-nigeria/ [Accessed 17 Dec 2018].

18 Ochalek J, Revill P, Manthalu G, et al. Supporting the development of a health benefits package in Malawi. BMJ Glob Health 2018;3:e000607.

19 Ochalek J, Claxton K, Revill P. CHE research paper 136: supporting the development of an essential health package: principles and initial assessment for Malawi. Centre for Health Economics, University of York, 2016. https://www.york.ac.uk/media/che/documents/papers/ researchpapers/CHERP136_EHP_Malawi_interventions.pdf

20 Jamison DT, Gelband H, Horton S, et al. Disease Control Priorities. In: Jamison DT, Gelband H, Horton S, et al, eds. Improving health and reducing poverty. 3rd edn. The World Bank, 2017. https:// openknowledge.worldbank.org/bitstream/handle/10986/28877/ 9781464805271. pdf? sequence=2\&isAllowed $=y$ 
21 Chalkidou K, Culyer AJ. Making choices on the journey to universal health care coverage: from advocacy to analysis. Value Health 2016;19:910-2.

22 Annex 3C. essential universal health coverage: interventions andPlatforms. Available: http://dcp-3.org/sites/default/files/chapters/ Annex\%203C Interventions\%20in\%20EUHC.pdf [Accessed 14 Feb 2018].

23 IHME. GBD compare IHME viz hub. Available: http://vizhub. healthdata.org/gbd-compare [Accessed 16 Nov 2018].

24 Zambia Ministry of Health. Zambia National health strategic plan 2017-2021, 2016. Available: http://dspace.unza.zm:8080/xmlui/ handle/123456789/5113 [Accessed 26 Nov 2018].

25 WHO. WHO guideline on syphilis screening and treatment for pregnant women. Available: http://www.who.int/reproductivehealth/ publications/rtis/syphilis-ANC-screenandtreat-guidelines/en/ [Accessed 28 Dec 2018].

26 Henry J Kaiser. The U.S. government and global neglected tropical disease efforts. The Henry J. Kaiser Family Foundation, 2018 https://www.kff.org/global-health-policy/fact-sheet/the-u-sgovernment-and-global-neglected-tropical-diseases/
27 CDC. Global Health - Neglected Tropical Diseases. Available: https:// www.cdc.gov/globalhealth/ntd/index.html [Accessed 18 Dec 2018].

28 Hauck K, Smith PC. The politics of priority setting in health: a political economy perspective. center for global development, working paper 4142015.

29 Claxton K, Ochalek J, Revill P, et al. Informing decisions in globa health: cost per DALY thresholds and health opportunity costs. F1000Research, 2017. Available: https://f1000research.com/ documents/6-467 [Accessed 14 Nov 2018].

30 Herricks JR, Hotez PJ, Wanga V, et al. The global burden of disease study 2013: what does it mean for the NTDs? PLoS Negl Trop Dis 2017;11:e0005424.

31 WHO. Neglected tropical diseases. Available: http://www.who.int/ neglected_diseases/en/ [Accessed 16 Nov 2018].

32 Kanyangarara M, Walker N, Boerma T. Gaps in the implementation of antenatal syphilis detection and treatment in health facilities across sub-Saharan Africa. PLoS One 2018;13:e0198622.

33 Ministry of Health and Sanitation. Sierra Leone basic package of essential health services 2015-2020, 2015. Available: https:// mohs2017.files.wordpress.com/2017/06/gosl_2015_basic-packageof-essential-health-services-2015-2020.pdf 